\title{
A study of drug utilization trends in acute coronary syndrome in intensive cardiac care unit at a tertiary care hospital, Mysore
}

\author{
Saranya Kalyanasundarram Lakshmi ${ }^{1}$, Hema Narasimhe Gowda ${ }^{2}$, \\ Kanchanahalli Siddegowda Sadananda ${ }^{3}$
}

\begin{abstract}
${ }^{1}$ Postgraduate, ${ }^{2}$ Professor, Department of Pharmacology, Mysore Medical College and Research Institute, Irwin road, Mysore 570001, Karnataka, India

${ }^{3}$ Associate professor, Department of Cardiology, Sri Jayadeva Institute of Cardiovascular Sciences and Research, Mysore, Karnataka, India
\end{abstract}

Received: 30 November 2016 Accepted: 26 December 2016

\section{*Correspondence to:}

Dr. Saranya Kalyanasundarram Lakshmi,

Email: drsarank188@gmail.com

Copyright: (C) the author(s), publisher and licensee Medip Academy. This is an openaccess article distributed under the terms of the Creative Commons Attribution NonCommercial License, which permits unrestricted noncommercial use, distribution, and reproduction in any medium, provided the original work is properly cited.

\begin{abstract}
Background: Acute Coronary Syndrome (ACS) is an emergency condition where usage of many drugs during its management in ICCU is common. This could be a potential cause for Polypharmacy, Potential Drug-Drug Interactions and increased Cost Burden on patients. The objective of the study was WHO criteria for prescription like, 1) Average number of drugs per prescription, 2) Percentage of drugs prescribed by Generic name, 3) Percentage of drugs with Injections prescribed, 4) Percentage of prescriptions with Antibiotics and 5) Percentage of drugs prescribed from the WHO Essential Drugs List.

Methods: After obtaining approval from Institutional Ethics Committee, an observational study was carried out among 125 patients in a tertiary care hospital, Mysore. Patients diagnosed with ACS admitted in Intensive Cardiac Care Unit (ICCU) for initial 48 hrs were included in the study. The prescriptions were analyzed for WHO criteria for prescription. The results were analyzed using Descriptive Statistics and T- test.

Results: In our present study the most common diagnoses were found to be ACS- Anterior wall myocardial infarction (36.8\%) and ACS-Inferior wall myocardial infarction (32.8\%). Hypertension (35.2\%) and Type 2 diabetes mellitus (29.6\%) were the frequently associated co-morbid conditions. Antiplatelet drugs $(100 \%)$ and Hypolipidemic drugs $(100 \%)$ were the most commonly prescribed, followed by Anti coagulants $(94.4 \%)$. The average number of drugs per prescription was $9.09 \pm 2.17$. Percentage of drugs prescribed by generic names was $37.29 \%$. The percentage of drugs prescribed from essential drug list was $50.84 \%$.
\end{abstract}

Conclusions: The present study provides valuable insight about the overall pattern of drugs used in Acute Coronary syndrome. Physician should be encouraged to prescribe drugs with generic name.

Keywords: Acute coronary syndrome, Drug utilization, Intensive cardiac care unit, Poly pharmacy, Prescription pattern, WHO prescription indicators

\section{INTRODUCTION}

Cardiovascular diseases (CVDs) are highly prevalent diseases globally, diagnosed in 80 million adults, i.e., one-third of the adult population. CVDs remain the most common cause of death, accounting for $35 \%$ of all deaths, i.e. almost one million deaths each year. Approximately one-fourth of these deaths are sudden.
More than $80 \%$ of the deaths occurred in low and middle income countries. In India, CVDs are the largest cause of mortality, accounting for around one-fourth of all deaths. ${ }^{1}$ Various studies from India have shown high prevalence of the disease, approaching approximately $11 \%$ in the urban population and $7 \%$ in the rural population across India. $^{2}$ 
The term acute coronary syndrome refers to a range of acute myocardial ischemic states. It encompasses unstable angina, non-ST segment elevation myocardial infarction (ST segment elevation generally absent), and ST segment elevation infarction (persistent ST segment elevation usually present). Myocardial infarction is a common presentation of ischemic heart disease. ${ }^{3}$

The treatment for Coronary Artery Disease involves the use of various categories of drugs namely antiplatelet drugs, anti-coagulants, anti-anginal drugs, beta blockers, angiotensin converting enzyme inhibitors (ACEI)/ angiotensin II receptor blockers (ARBs), Calcium channel blockers, diuretics, etc. ${ }^{4}$ There are many drugs prescribed in a single patient simultaneously in ICCU with the aim of maximizing efficacy in a particular condition. Prescribing rationally in ICCU is important to minimize chances of drug interactions, adverse drug reactions and unduly high cost of treatment. ${ }^{1}$

Instituting appropriate therapy is essential for a favourable outcome of the patient and to decrease mortality and morbidity. Clinicians often face challenges in selecting, initiating and individualizing appropriate drug therapy for patients admitted in the emergency medicine ward. Monitoring the trends in drug utilization in emergency medicine can provide insight into major health-care problems. ${ }^{5}$ Rational drug prescribing is defined as the use of the least number of drugs to obtain the best possible effect in the shortest period and at a reasonable cost. ${ }^{6}$ Hence this prospective cross-sectional study was undertaken with the objectives to evaluate the drug use pattern in patients admitted to the emergency ward (ICCU) for initial 48 hours of hospitalization.

\section{METHODS}

This observational study was carried out for a period of two months from July - August, 2015. After obtaining approval from Institutional Ethics Committee, a prospective observational study was carried out in patients with ACS admitted in the Intensive Cardiac Care Unit (ICCU) at Sri Jayadeva Institute of Cardiovascular Sciences and Research, KR Hospital Campus, Mysore, over a period of 2 months. Patients of either sex who were diagnosed with Acute Coronary Syndrome and admitted in ICCU for atleast $48 \mathrm{hrs}$ were included in the study. Patients who did not give consent or died within initial $24 \mathrm{hrs}$ were excluded from the study.

After obtaining a Written Informed Consent of patient or relative, demographic data like name, age, sex, address and clinical data including diagnosis, detailed history of illness, past history, family history were noted and recorded on the case record form. The details of drug therapy including the drugs prescribed, dose and the frequency were also noted using the Medical Record Form. The WHO prescription indicators analyzed were,

1. Average number of drugs per prescription
2. Percentage of drugs prescribed by Generic name

3. Percentage of drugs with Injections prescribed

4. Percentage of prescriptions with Antibiotics

5. Percentage of drugs prescribed from the WHO Essential Drugs List.

The statistical tests applied were Descriptive statistics and T-test. Statistical analysis was done by using the SPSS software - version 21 and Microsoft excel.

\section{RESULTS}

The mean age group of the patients was found to be 56.39 \pm 12 .8. In our present study 125 patients were analyzed out of which 93 were males and 32 were females (Figure 1).

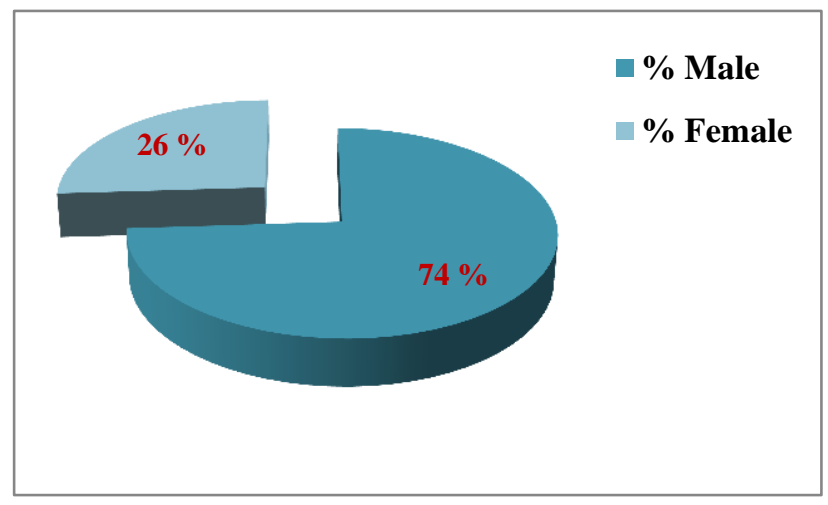

Figure 1: Gender distribution.

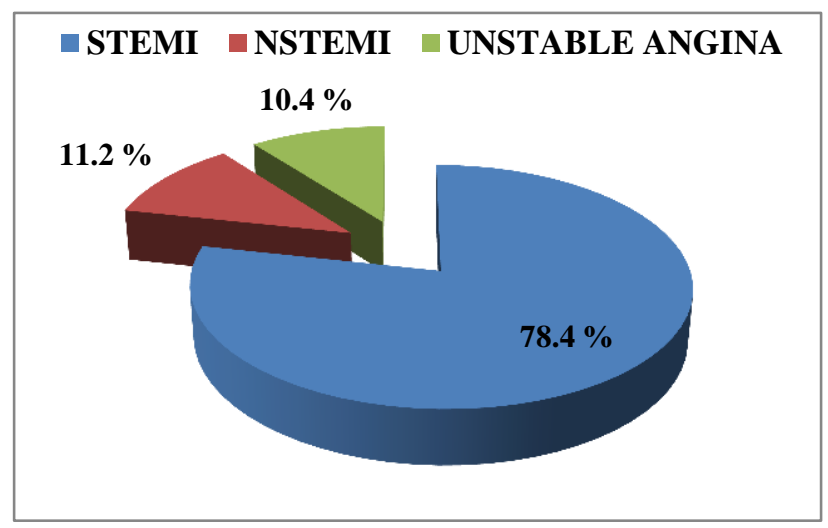

Figure 2: Distribution of types of ACS (Acute Coronary Syndrome).

The most common diagnoses were found to be STelevation Myocardial infarction like ACS- Anterior wall myocardial infarction (36.8\%) and ACS-Inferior wall myocardial infarction $(32.8 \%)$ as shown in Figure 2. Hypertension $(22.4 \%)$ and Type 2 diabetes mellitus $(12 \%)$ were the frequently associated co-morbid conditions. Antiplatelet drugs like Aspirin (100\%) and Clopidogrel (100\%) and Hypolipidemic drug like Atorvastatin (100\%) were the most commonly prescribed, followed by Anti coagulant like Heparin $(94.4 \%)$. 
The average number of drugs per prescription was $9.09 \pm 2.17$. Percentage of drugs prescribed by generic names was $37.29 \%$. The percentage of drugs prescribed from essential drug list was $50.84 \%$. Injections contributed around $28.3 \%$ among the total drugs prescribed. The percentage of encounters with antibiotics prescribed was found to be $15.2 \%$ as shown in Figure 3 and Table 1.

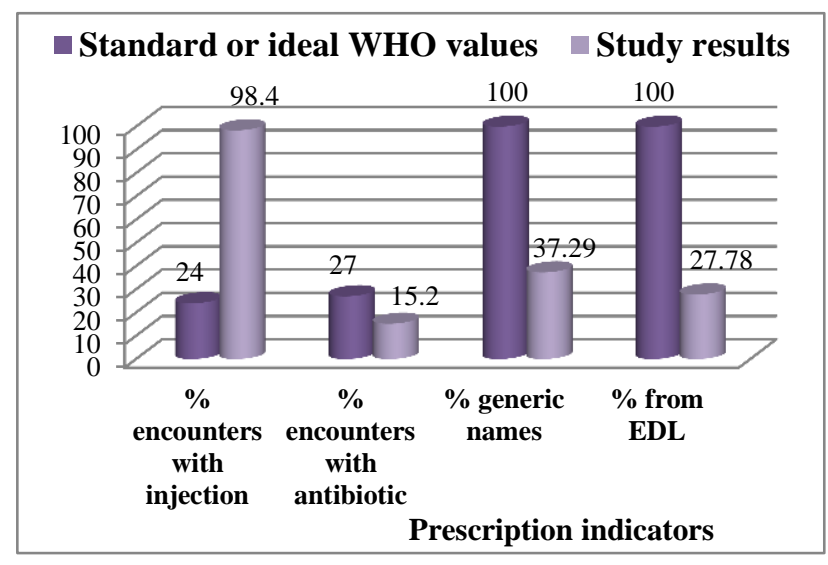

Figure 3: WHO prescription indicators.

Table 1: WHO prescription indicators: standard values vs study values.

\begin{tabular}{|llll|}
\hline S.no & $\begin{array}{l}\text { Prescribing } \\
\text { Indicators assessed }\end{array}$ & $\begin{array}{l}\text { Standard } \\
\text { or ideal }\end{array}$ & $\begin{array}{l}\text { Study } \\
\text { results }\end{array}$ \\
\hline 1. & $\begin{array}{l}\text { Average number of } \\
\text { drugs per encounter }\end{array}$ & $1.6-1.8$ & $9.09 \pm 2.17$ \\
\hline 2. $\quad \begin{array}{l}\text { Percentage of } \\
\text { encounters with an } \\
\text { injection prescribed }\end{array}$ & $13.4-24.1$ & 98.4 \\
\hline $3 . \quad \begin{array}{l}\text { Percentage of } \\
\text { encounters with an } \\
\text { antibiotic prescribed }\end{array}$ & $20.0-26.8$ & 15.2 \\
\hline 4. $\quad \begin{array}{l}\text { Percentage of drugs } \\
\text { prescribed by generic } \\
\text { name }\end{array}$ & 100 & 37.29 \\
\hline 5. & $\begin{array}{l}\text { Percentage of drugs } \\
\text { from essential drug } \\
\text { list }\end{array}$ & 27.78 \\
\hline
\end{tabular}

\section{DISCUSSION}

Cardiovascular diseases are the leading cause of disability and morbidity and mortality worldwide, affecting developed and developing countries. Much of the burden of cardiovascular disease is due to acute coronary syndrome (ACS). This syndrome includes acute myocardial infarction (AMI) with and without ST segment elevation and unstable angina (UA) and is characterized by ischemia and necrosis of the heart muscle due to an athero-thrombotic event. ${ }^{7}$

The drug utilization study has been conducted widely and it is being carried out in different health care setups. Such studies are helpful to determine the behaviour of the use of medicines in a society. A survey based on prescription is considered to be one of the most cost effective methods to determine the prescribing approach of physicians. ${ }^{6}$

The present study is an attempt to evaluate the pattern of prescriptions of the patients with ACS admitted in ICCU in a tertiary care teaching hospital, Mysore.

In our study mean age of patient was $56.39 \pm 12.8$ years which was comparable to other studies done by Christian $\mathrm{RP}$ et al (54.67 \pm 13.42 years) ${ }^{1}$ and Chaudhari $\mathrm{P}$ et al (57.6 \pm 11.09 years). ${ }^{8}$ This shows that acute coronary syndrome is more in this age group. In our study males (93) were more common than the females (32), which was comparable to other studies which say that cardiovascular emergencies were more common in males than the females. 5,6

In our study the most common diagnoses were found to be ST-elevation MI (STEMI) including ACS- Anterior wall myocardial infarction $(36.8 \%)$ and ACS-Inferior wall myocardial infarction (32.8\%). This is similar to the studies done by González-Pacheco et al (STEMI-51.3\%), Giugliano RP et al (STEMI- 29-47\%) and Auer et al (STEMI- 39\%). ${ }^{9-11}$ It was said in a study that there has been a substantial reduction in the incidence of STEMI and a subsequent increase in the incidence of NSTEMI. ${ }^{12}$ The exact reason for this changing trend is not known. But this can be probably due to improved treatment strategies for STEMI. Since there is changing trend the management approach and treatment strategies for NSTEMI should be still more improvised to higher standards.

Hypertension (22.4\%) and Type 2 diabetes mellitus $(12 \%)$ were the frequently associated co-morbid conditions in our study which was comparable to a study where hypertension $(46.91 \%)$ was the most common associated disease in cardiovascular emergencies and other studies where hypertension followed by diabetes mellitus were the most common co-morbidities associated with acute coronary syndrome. ${ }^{1,6,13,14}$ This could be probably because these two systemic diseases are highly prevalent in India. Both the diseases hypertension and diabetes mellitus can severely affect the blood vessels.

In our study antiplatelet drugs like Aspirin and Clopidogrel were the most commonly prescribed drugs which was similar to other studies. ${ }^{8,9}$ The association of physicians of India recommends that all patients with myocardial infarction should receive dual antiplatelet therapy. ${ }^{8}$ It was told in another study that Aspirin along with Clopidogrel may offer benefits over either drug used alone in Ischemic heart disease associated with Hypertension and Diabetes mellitus. ${ }^{4}$ In our study Atorvastatin was the preferred Hypolipidemic drug given to all patients $(100 \%)$ as similar to another study. ${ }^{15}$ 
The average number of drugs per prescription was $9.09 \pm 2.17$ which was comparably higher when compared to other studies done by Afroz et al (8.8) and Nagabushan et al (7.8 \pm 2.2$).{ }^{6,16}$ But our finding on average number of drugs was similar to a study done on geriatric patients showing 9.37 drugs per prescription. ${ }^{17}$ This difference in values could be probably due to variation in associated co-morbid conditions among population and the difference in prescription pattern among physicians. It is necessary to keep mean number of drugs as low as possible to minimize the adverse effects, potential drugdrug interactions and to reduce the cost of treatment. Also the WHO standard or ideal value for average number of drugs per prescription was 1.6-1.8. ${ }^{18,19}$ Though our study showed polypharmacy, the associated comorbid illnesses warrant increased drug prescription.

In our study, Percentage of drugs prescribed by generic names was $37.29 \%$ which was found to be lower when compared to a study done by Nagabushan et al (52.9\%), but was higher when compared to other studies done by Ghosh et al and Afroz et al. ${ }^{6,15,16}$ The physician should concentrate on prescribing drugs with their generic names to the maximum in order to minimize the cost-burden on the patients.

In a study done in emergency department, the drugs prescribed from the WHO essential medicine list comprised only $64.94 \%$ of drugs. It was also said that, this proportion should have been higher since this list of drugs is prepared with regard to public health relevance, evidence on efficacy and safety of the drugs, and comparative cost effectiveness. ${ }^{13}$ This holds true for our study also since the percentage of drugs prescribed from essential drug list was only $50.84 \%$ which is still a lower value when compared to the study mentioned above.

Injections contributed around $28.3 \%$ among the total drugs prescribed which is lower when compared to previous studies done by Kaur $\mathrm{S}$ et al (75.17\%) and Nagabushan $\mathrm{H}$ et al (100\%). ${ }^{6,13}$ However in another study done in patients with ACS, the number of injectables prescribed was nil $(0 \%)$ during the follow-up visits. ${ }^{15}$ This shows that the need for injections is very high during the emergency or acute management of ACS than during the follow-up visits. However in our study the physicians have tried to minimize the number of injectables even during the emergency management (for initial $48 \mathrm{hrs}$ ) probably to avoid complications and to decrease the cost burden.

The percentage of encounters with antibiotics prescribed was found to be $15.2 \%$ which was less when compared to studies done by Chandana et al $(25 \%)$ and Sri Chandana $\mathrm{M}$ et al (19.5\%). ${ }^{3,18}$ The most common group of antibiotic prescribed was Cephalosporins (Ceftriaxone) which was similar to a study done by Nagabushan et al. ${ }^{6}$ The use of appropriate antibiotics in order to treat associated infection (respiratory, gastro-intestinal etc.) is justifiable.
The strengths of our study are the study is done on acute coronary syndrome patients which is a critical emergency condition where the chances of inappropriate/ overprescription of drugs can happen; a good sample size and the results were compared with standard WHO guidelines.

The limitation is that the study could have been extended till the patients get discharged from the hospital and the cost analysis is not done.

\section{CONCLUSION}

The over-all prescription patterns involved in our study is satisfactory. Polypharmacy could be reduced by individual patient approach while treating. Writing prescriptions in generic names to the maximum could reduce the cost burden on the patient and brings about rationality in prescription. The less number of injectable prescribed in our study is appreciable imposing relatively less cost burden on patients. We conclude that forming an appropriate hospital protocol for the emergency management of Acute Coronary Syndrome beforehand could prevent the polypharmacy, unwanted drug- drug interactions and cost burden on the patients.

\section{ACKNOWLEDGEMENTS}

I thank Dr. B. M. Parashivamurthy, Professor and Head, Department of Pharmacology, MMC and RI, Mysore for his support and encouragement to carry-out this study.

I wish to thank all the Doctors and Staff members, ICCU, Department of Cardiology, Sri Jayadeva Institute of Cardiovascular Sciences, KR hospital Campus, Mysore, for their support.

\section{Funding: No funding sources Conflict of interest: None declared}

Ethical approval: The study was approved by the Institutional Ethics Committee of Sri Jayadeva Institute of Cardiovascular Sciences, Bangaluru, Karnataka, India.

\section{REFERENCES}

1. Christian RP, Rana DA, Malhotra SD, Patel VJ. Evaluation of rationality in prescribing, adherence to treatment guidelines and direct cost of treatment in intensive cardiac care unit: A prospective observational study. Indian J Crit Care Med. 2014;18(5):278-84.

2. Zachariah G, Harikrishnan S, Krishnan MN, Mohanan PP, Sanjay G, Venugopal K, et al. Prevalence of coronary artery disease and coronary risk factors in Kerala, South India: A population survey- Design and methods. Indian Heart J. 2013;65(3):243-9.

3. Chandana N, Subash V, Kumar VG. A prospective study on drug utilization of cardiac unit in acute 
myocardial infarction of hosptalized patients. Inter. J. of Pharmacotherapy. 2013;3(1):6-11.

4. Jyothi K, Saleem T, Vineela L, Gopinath C, Reddy K. A Retrospective Drug Utilization Study of Antiplatelet Drugs in Patients with Ischemic Heart Disease. International Journal of Medical, Health, Biomedical, Bioengineering and Pharmaceutical Engineering. 2015;9(7):605-8.

5. Barot PA, Malhotra SD, Rana DA, Patel VJ, Patel KP. Drug utilization in emergency medicine department at a tertiary care teaching hospital: A prospective study. J Basic Clin Pharma. 2013;4:7881.

6. Nagabushan H, Roopadevi HS, Prakash GM, Pankaja R. A prospective study of drug utilization pattern in cardiac intensive care unit at a tertiary care teaching hospital. Int J Basic Clin Pharmacol. 2015;4:579-83.

7. Gaedke MA, Da Costa JSD, Manenti ERF, Henn RL, Paniz VMV, Nunes MF, et al. Use of medicines recommended for secondary prevention of acute coronary syndrome. Rev. Saúde Pública 2015;49:88.

8. Choudhary P, Agrawal JM, Malhotra SD, Patel VJ. Drug utilization pattern in acute coronary syndrome at tertiary care hospital: a prospective cross-sectional observational study. Int J Basic Clin Pharmacol. 2016;5:513-6.

9. González-Pacheco H, Vargas-Barrón J, Vallejo M, Piña-Reyna Y, Altamirano-Castillo A, Sánchez-Tapia P. Prevalence of conventional risk factors and lipid profiles in patients with acute coronary syndrome and significant coronary disease. Ther Clin Risk Manag. 2014;10:815-23.

10. Giugliano RP, Braunwald E. The Year in Acute Coronary Syndrome. J Am Coll Cardiol. 2014;63(3):201-4.

11. Auer R, Gencer B, Räber L, Klingenberg R, Carballo S, Carballo D, et al. Quality of Care after Acute Coronary Syndromes in a Prospective Cohort with Reasons for Non-Prescription of Recommended Medications. PLoS One 2014; 9(3): e93147.

12. Smith JN, Negrelli JM, Manek MB, Hawes EM, Viera AJ. Diagnosis and management of acute coronary syndrome: An evidence-based update. J Am Board Fam Med. 2015;28:283-93.

13. Kaur S, Rajagopalan S, Kaur N, Shafiq N, Bhalla A, Pandhi P. Drug Utilization Study in Medical Emergency Unit of a Tertiary Care Hospital in North India. Emerg Med Int. 2014:1-5.

14. Pendhari SR, Chaudhari DR, Burute SR, Bite BM. A Study on the Drug Utilization Trends in the Cardiovascular Emergencies in a Tertiary Care Hospital. J Clin Diagn Res. 2013;7(4):666-70.

15. Ghosh A, Das AK, Pramanik S, Saha UK. Drug utilization study in patients of acute coronary syndrome on follow-up visits at a tertiary care centre in Kolkata. Asian Journal of Pharmacy and Life Science. 2012;2(2):155.

16. Afroz F, Parveen F, Ara F, Iqbal MJU, Saha RR, Rozario RJ. Patterns of Drug Utilization in Cardiology Department of a Tertiary Level Hospital in Bangladesh. Bangladesh J. physiol. pharmacol. 2014;28(1 and 2):1-4.

17. Jhaveri BN, Patel TK, Barvaliya MJ, Tripathi CB. Drug utilization pattern and pharmacoeconomic analysis in geriatric medical in-patients of a tertiary care hospital of India. J Pharmacol Pharmacother. 2014;5(1):15-20.

18. Chandana SM, Lakshmi A, Sathish K. An evaluation of drug use patterns in Acute Coronary Syndrome patients using WHO prescribing indicators. World J Pharm Res. 2015;4(8):2095-103.

19. Demeke B, Molla F, Assen A, Melkam W, Abrha S, Masresha B, et al. Evaluation of drugs utilization pattern using who prescribing indicators in ayder referral hospital, Northern Ethiopia. Int J Pharm Sci Res. 2015;6(2):343-7.

Cite this article as: Saranya KL, Gowda HN, Sadananda KS. A study of drug utilization trends in acute coronary syndrome in intensive cardiac care unit at a tertiary care hospital, Mysore. Int J Basic Clin Pharmacol 2017;6:344-8. 